\title{
AS FORMAS DE INTERVENÇÃO PARA APRIMORAR A FORMAÇÃO DO PROFESSOR FORMADOR QUE ATUA NO ENSINO SUPERIOR: UMA REVISÃO
}

\author{
THE WAYS OF INTERVENTION TO IMPROVE THE TRAINING OF THE \\ PROFESSOR EDUCATOR: A REVIEW
}

\section{Graucineide Maria de Alcântara ${ }^{1}$ Islane Cristina Martins ${ }^{2}$}

RESUMO: Introdução: A formação para o ensino superior tem sido tema de vários estudos e discussões no Brasil e em outros países. Estudos vêm apontando a insuficiência do saber pedagógico ao domínio específico, o que acaba refletindo na qualidade do ensino e na aprendizagem. Objetivo: Realizar uma revisão integrativa da literatura a fim de investigar as formas de intervenção para aprimorar a formação do professor formador no ensino superior. Materiais e Métodos: Foi feita uma busca das referências nas bases Periódicos CAPES e Google Acadêmico em maio de 2021. A busca permitiu a identificação de quatro artigos que se adequaram aos critérios estabelecidos. Resultados: Foi observado que dos 04 artigos revisados $100 \%$ apontaram que, a formação continuada do docente universitário, é uma maneira do professor melhorar sua atuação, a fim de inovar e qualificar sua prática, ofertando assim, um ensino e aprendizagem mais significativos. Conclusão: Os artigos indicam que o desenvolvimento profissional docente é uma forma de intervenção essencial à atuação do professor universitário. A participação e o engajamento docente, nesse sentido, são de extrema importância, para que se alcance um processo de ensino aprendizagem mais significativo.

Palavras-chave: Intervenção. Formação Continuada. Docente Universitário.

ABSTRACT: Introduction: The training for higher education has been the theme of various studies and discussions in Brazil and Other countries. Studies have revealed the insufficiency of pedagogical knowledge in the specific domain, which ends up reflecting on the quality of teaching and learning. Objective: Carrying out an integrative literature review for investigating the forms of intervention to improve the training of professor educators in Higher Education. Materials and Methods: It

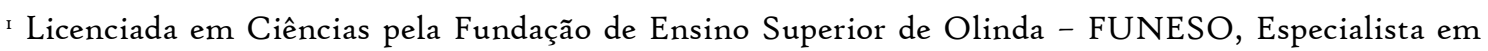
Microbiologia Aplicada pela Universidade Federal Rural de Pernambuco - UFRPE. Professora da Secretaria Estadual de Educação de Pernambuco e da Secretaria de Educação da cidade de Recife - PE. E-mail: graucineide@hotmail.com.

${ }^{2}$ Doutora em Neurociências pelo programa de pós-graduação em Neuropsiquiatria e Ciências do Comportamento-UFPE.E-mail:islamemartins@gmail.com.
} 
was made a Search for references in the CAPES and Scholar Google databases in Maio 202I. The search allowed the identification of 4 articles that met the established criteria. Results: It was noted that from the 4 articles reviewed, Ioo\% pointed out that, the further education of the university professor is a way for the professor to improve his performance, to innovate and qualify his practice, therefore offering a more significant teaching and learning. Conclusion: The articles indicate that the professor professional development is a form of intervention that is essential to the performance of the university professor. Teaching participation and engagement, in this sense, is extremely important, to achieve a more significant teacher-learning process.

Keyword: Intervention. Further Education. University Professor.

\section{INTRODUÇÃO}

Buscando o significado de intervenção no dicionário Aurélio, encontramos: ato de intervir; interferência. Em educação, refere-se à ação em que o ensino e aprendizagem estão em processo de inter-relação constante (SOARES, 2005).

Sendo assim, quando o processo de ensino e aprendizagem sofre ruptura sempre que um problema é detectado, no intuito de solucioná-lo e ofertar um ensino de qualidade, intervenções podem ser feitas (ABREU, 2020)

Nesse sentido, espera-se que intervenções sejam implementadas no Ensino Superior, transformando conhecimentos teóricos em práxis pedagógicas, que culminarão em uma aprendizagem exitosa, modificando os sujeitos que dela se apropriam (THERRIEN; DIAS; LEITINHO, 20I6).

Nessa perspectiva, entender a formação como processo permanente de aprimoramento, onde se conserva os valores essenciais à prática, mantendo a convicção da transformação evolutiva na carreira, é um ponto a ser compreendido pelo docente (FÁVERO; PAZINATO, 2016).

Sendo assim, entende-se o desenvolvimento profissional do docente universitário, como uma intervenção em busca do aprimoramento do ensino e aprendizagem, num processo de transformação e construção do conhecimento (FÁVERO; PAZINATO, 2016).

No entanto, a LDB (BRASIL, 1996) não faz exigências, no que tange a prática pedagógica para o ensino superior. A titulação de pós-graduação é o nível esperado para atuar como professor universitário (VILELA, 20I6).

Por isso, percebe-se nas instituições, um quadro de professores com uma formação fragilizada, carente de conhecimentos pedagógicos, para atuar em sala de aula, enquanto mediador do conhecimento discente (FÁ VERO; PAZINATO, 2016).

Sendo assim, a ação pedagógica do docente universitário é influenciada pelas experiências curriculares obtidas na formação inicial, centrada em um modelo de educação tradicional, novista e tecnocrata (FÁVERO; PAZINATO, 2016, apud. LAMPERT, 1999). 
Neste sentido, é fundamental que o professor busque se atualizar, modificar suas ações, para atender as novas demandas sociais, que apresentar distintas necessidades a cada dia (HUBERT; FERNANDES; GOETTEMS, 2015)

Porém, no ensino superior, nota-se uma carência de diretrizes para formação docente, sendo as contratações de professores, com conhecimentos voltados, mais à pesquisa, um dos problemas a serem solucionados (FÁVERO; PAZINATO, 2016).

Desse modo, percebe-se que "a realidade denuncia a urgência em promover os processos formativos dos profissionais envolvidos no contexto do ensino superior (ES), como forma de melhorar a qualidade do ensino" (FÁ VERO; PAZINATO, 2016).

Nesse sentido, o artigo $45^{\circ}$ da Lei de Diretrizes de Bases (LDB) ressalta que: "A educação superior será ministrada em instituições de ensino superior, pública ou privada com variados graus de abrangência ou especialização" (BRASIL, 1996).

Porém, a organização do ensino superior no Brasil tem seus registros datados de I808, onde surgiram as escolas de medicina no estado do Rio de Janeiro e na Bahia (FÁVERO; PAZINATO, 2016).

Sendo assim, a primeira instituição de ensino superior no Brasil surgiu no ano de 1912, após a Proclamação da República, e da regulamentação da constituição em I89I no estado do Paraná (FÁVERO; PAZINATO, 2016).

Mas, o número de instituições universitárias no Brasil vem crescendo nos sistemas público e privado desde 1930, independente do atraso na ativação dessas instituições, quando se compara a outros países da América Latina (FÁVERO; PAZINATO, 2016).

Desse modo, o ensino superior necessita de professores mais preparados, para que se oferte à sociedade profissionais mais qualificados. Para isso, é preciso que o docente se mantenha em formação ao longo de sua carreira, inteirando-se das inovações, refletindo sobre sua prática, articulando-se com seus pares na troca de experiências inovadoras e exitosas, ou seja, busque meios que contribuam para o seu desempenho profissional, o que o levará à uma atuação significativa, onde o aluno possa perceber a importância do conhecimento para sua vida.

Por isso, o objetivo do presente estudo foi realizar uma revisão integrativa da literatura a fim de investigar quais as formas de intervenção para aprimorar a formação do professor formador no Ensino superior.

\section{MATERIAIS E MÉTODOS}

Foi feito um levantamento da literatura em março de 202I nas bases de dados Periódicos CAPES e Google Acadêmico. "Os descritores utilizados foram os seguintes: "Intervenção" AND "Formação" AND "Professor" AND "Superior" AND "Intervention” AND "Training” AND 'Teacher" AND "University" em todas as bases de dados. Foram selecionados 04 artigos sendo incluídos segundo os critérios de elegibilidade conforme a Figura I. Os critérios de inclusão foram: artigos nos idiomas inglês e português, nos últimos cinco anos, envolvendo as formas de 
intervenção para aprimorar a formação do professor formador que atua no ensino superior. Os critérios de exclusão foram artigos de revisão de literatura.

FigurA r. FluXograma E CRITÉRIOS DE SELEÇÃo E INCLUSÃo dOS ARTIGOS
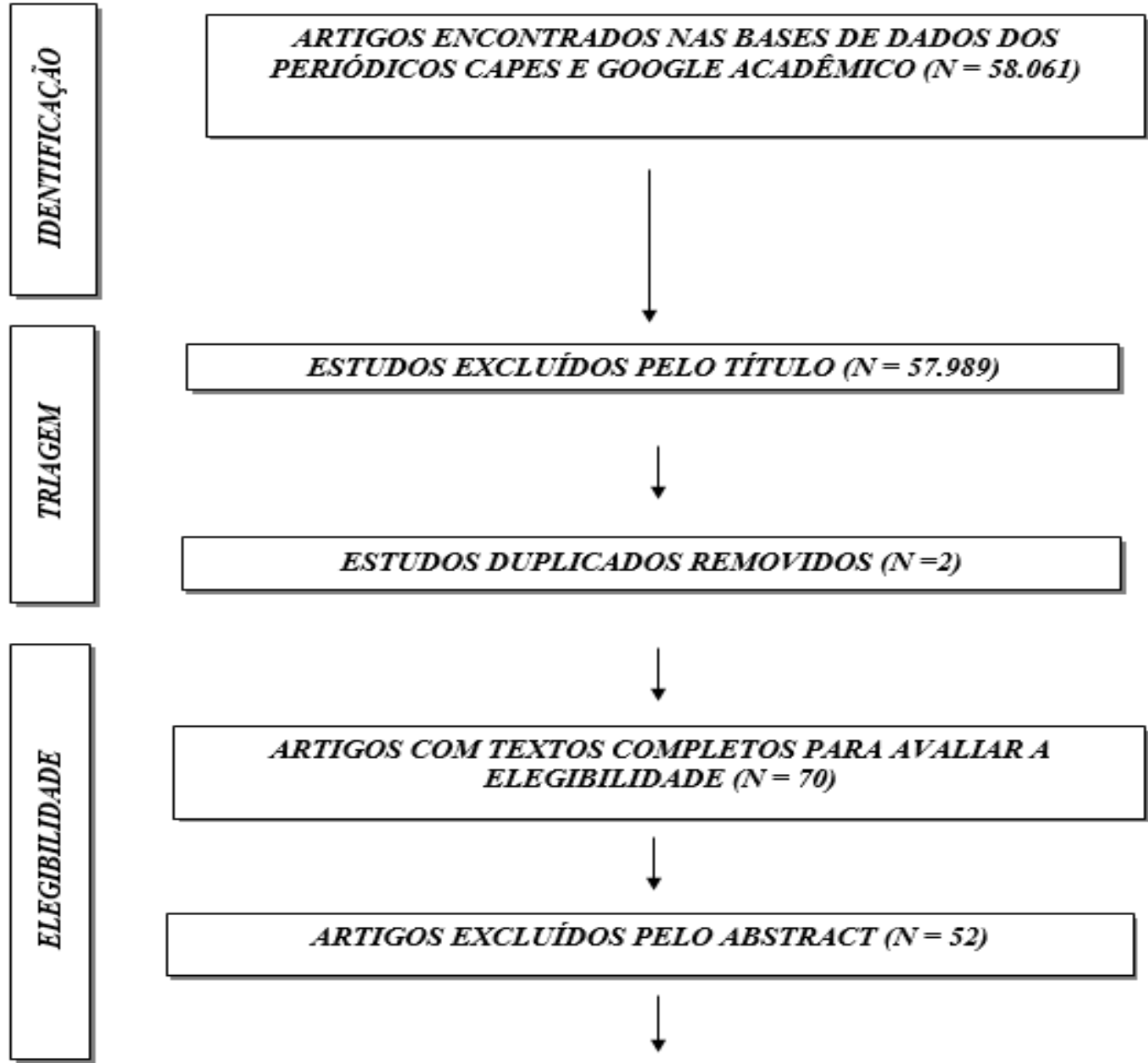

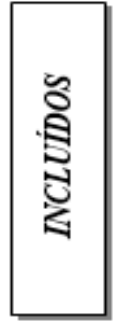

ARTIGOS EXCLUIDOS A PARTIR DA LEITURA DO TEXTO COMPLETO $(\mathrm{N}=14)$

\section{RESULTADOS}

Os resultados do presente estudo encontram-se na Tabela I. 
Revista Ibero- Americana de Humanidades, Ciências e Educação- REASE ${ }_{\text {open }}$ Access

Tabela I - Demonstrativo dos artigos que integram a revisão integrativa

\begin{tabular}{|c|c|c|c|c|c|}
\hline$\# N$ & Data & Título & Autores & Periódico & Objetivos \\
\hline I & 2018 & $\begin{array}{lr}\text { Formaação } & \text { docente } \\
\text { no } & \text { contexto } \\
\text { brasileiro } & \text { das } \\
\text { Instituições } & \text { Federais } \\
\text { de } & \text { Educação } \\
\text { Superior } & \end{array}$ & $\begin{array}{l}\text { Ailton Paulo de } \\
\text { Oliveira Júnior; } \\
\text { Martha Maria Prata- } \\
\text { Linhares; Acir Mário } \\
\text { Karwoski }\end{array}$ & $\begin{array}{l}\text { Ensaio: aval. pol. } \\
\text { públ.Educ. [online] }\end{array}$ & $\begin{array}{l}\text { Destacar as ações apresentadas pela a } \\
\text { IFES no Brasil para a promoção da } \\
\text { formação permanente dos docentes } \\
\text { do ensino superior. }\end{array}$ \\
\hline 2 & 2016 & $\begin{array}{lr}\text { A } & \text { pedagogia } \\
\text { universitária e suas } \\
\text { implicações } & \text { para } \\
\text { uma } & \text { prática } \\
\text { reflexiva } & \end{array}$ & $\begin{array}{l}\text { Altair Alberto Fávero; } \\
\text { Aldiciane Pazinato }\end{array}$ & $\begin{array}{l}\text { Revista de Ciências } \\
\text { Humanas } \\
\text { Educação }\end{array}$ & $\begin{array}{l}\text { Entender como a formação } \\
\text { permanente de professor se dá no } \\
\text { ensino superior, na perspectiva de } \\
\text { uma prática reflexiva. }\end{array}$ \\
\hline 3 & 2016 & $\begin{array}{l}\text { Docência } \\
\text { Universitária }\end{array}$ & $\begin{array}{l}\text { Jacques Therrien Ana } \\
\text { Maria Iório Dias } \\
\text { Meirecele Calíope } \\
\text { Leitinho }\end{array}$ & Em Aberto & $\begin{array}{l}\text { Reconhecer que o conhecimento } \\
\text { para a atuação pedagógica e da } \\
\text { pesquisa, é essencial à formação } \\
\text { docente do ensino superior, bem } \\
\text { como a integração entre as ciências } \\
\text { de forma interdisciplinar. }\end{array}$ \\
\hline 4 & 2016 & $\begin{array}{lr}\text { Docência } & \\
\text { Universitária: } & \text { Um } \\
\text { estudo sobre } & \mathrm{a} \\
\text { experiência } & \mathrm{da} \\
\text { Universidade } & \\
\begin{array}{l}\text { Federal } \\
\text { Uberlândia }\end{array} & \text { de } \\
\begin{array}{l}\text { Formação de } \\
\text { professores }\end{array} & \text { seus } \\
\end{array}$ & Naiara Sousa Vilela & $\begin{array}{lr}\begin{array}{l}\text { Dissertação } \\
\text { Mestrado }\end{array} & \text { de } \\
\text { apresentada } & \text { ao } \\
\text { Programa de } & \text { Pós- } \\
\text { graduação } & \text { em } \\
\begin{array}{l}\text { Educação, } \\
\text { Repositório }\end{array} & \\
\text { da Uigital } & \end{array}$ & $\begin{array}{l}\text { Examinar o desempenho na } \\
\text { formação de docentes do ensino } \\
\text { superior, que atuam nas práticas } \\
\text { permanentes para melhoria da } \\
\text { qualificação profissional. }\end{array}$ \\
\hline
\end{tabular}

Com base nos estudos obtidos, percebe-se que as IFES vêm buscando desenvolver um trabalho traçado em ações como: (I) institucionalização de programas de formação docente em seus núcleos; (2) A definição de princípios de formação universitária nas IFES como, por exemplo, a valorização programas de formação de professores, junto a da sugestão á SESu fomento financeiro.

O estudo evidencia a necessidade de intervenções que possam transformar a pedagogia utilizada pelos docentes do ensino superior. Refletir sobre a prática do professor é uma forma de intervir no processo de ensino e aprendizagem, a fim de dar significância ao que se constrói junto ao aluno. As IES precisam de docentes bem qualificados, e isso se refletirá na formação dos futuros profissionais. Nesse sentido, torna-se evidente a importância da pedagogia reflexiva para a atuação do professor, no intuito de repensar e aprimorar sua prática. A reflexão sobre a própria forma de conduzir um trabalho em sala de aula leva a autoavaliação, e consequentemente, ao replanejamento do próprio trabalho, no sentido de transformar, de um modo inovador, sua prática, intervindo na qualidade do ensino e da aprendizagem.

Contudo, sabe-se que, um país, que busca seu desenvolvimento e independência, deve apresentar um sistema de ensino superior consistente. A formação continuada do docente precisa conciliar pesquisa e a prática pedagógica, pois são de suma importância para a profissionalização do professo do ensino superior e, para a construção do conhecimento discente. A formação permanente destes docentes tem que fornecer a condição, para que se perceba a necessidade da compreensão e da aplicabilidade da interdisciplinaridade e multidisciplinaridade, culturalismo; multiculturalismo, enfim, intervenções que enriqueçam, e proporcionem mais qualidade ao ensino e aprendizagem.

Os resultados mostram que, $29 y$ gicipação docente nas formações permanentes levou estes a reflexão e compreensão de suas ações e a construção e reconstrução de conhecimentos, para a edificação de sua identidade profissional. Nesse viés, percebe-se que é preciso propostas direcionadas à formação docente universitária, a fim de promover o desempenho profissional do professor e a transformação na sua atuação pedagógica. 


\section{DISCUSSÃO}

O objetivo do presente artigo foi investigar as formas de intervenção para aprimorar a formação do professor formador que atua no ensino superior, a fim de melhorar a qualidade do ensino-aprendizagem nas universidades.

Nesse viés, atualmente, nota-se que diretrizes estão sendo elaboradas, pelas IFES, para impulsionar a formação continuada de seus docentes embora, seja um propósito á ser consolidado a longo prazo.

Contudo, ações governamentais têm sido implementadas, em consonância com as IFES, como incentivo aos programas de profissionalização docente, a fim de melhorar o ensino e aprendizagem propostos (JÚNIOIR; LINHARES; KARWOSKI, 2018)

Porém, segundo (VILELA, 2016, apud MASETTO, 1998), para que se entenda as demandas específicas à prática docente universitária, faz-se necessário, reunir saberes particulares deste ofício, algo mais que títulos e diplomas.

Isso se deve ao fato de que, com o aparecimento das universidades no Brasil, no princípio do século XX, a docência pedagógica, centrada no ensino, tinha como foco a disseminação de vários conhecimentos (VILELA, 2016).

Todavia, a prática docente e diplomas não são suficientes, para a docência universitária do presente século. A composição de um conhecimento particular, criado e recriado, nas universidades, é de suma importância à atuação profissional (VILELA, 2016)

Neste sentido, é fundamental que o professor busque se atualizar, modificar suas ações, para atender às novas demandas sociais, que apresentará distintas necessidades a cada dia (HUBERT; FERNANDES; GOETTEMS, 2015).

No entanto, a LDB (BRASIL, 1996) não faz exigências, no que tange a prática pedagógica para o ensino superior. A titulação de pós-graduação é o nível esperado para atuar como professor universitário (VILELA, 2016).

Desse modo, as cadeiras docentes, nas universidades, são ocupadas por titulares como bacharéis e licenciados, mestres e doutores com formação em um campo limitado do conhecimento, aquém do saber pedagógico (VILELA, 2016).

No entanto, docentes iniciantes na carreira se sentem perdidos ao se depararem com a sala de aula, tendo que exercer uma função a qual não estão preparados, por possuir baixo ou nenhum conhecimento pedagógico (VILELA, 2016).

Porém, buscando transformações que tenham sentido social, cabe ao docente manter-se atualizado em sua área de conhecimento, no que tange ao ensino e aprendizagem (HUBERT; FERNANDES; GOETTEMS, 2015)

Nesse viés, o professor universitário precisa desempenhar sua atividade com compromisso e responsabilidade, visando à formação de pessoas com pensamentos crítico-reflexivo (HUBERT; FERNANDES; GOETTEMS, 2015). 
Porém, a ação pedagógica docente universitária é influenciada pelas experiências curriculares obtidas na formação inicial, centradas em um modelo de educação tradicional, novista e tecnocrata (FÁVERO; PAZINATO, 20I6, apud LAMPERT, 1999).

Contudo, (FÁVERO; PAZINATO, 20I6) enfatiza o valor do estudo docente contínuo, evidenciando que o interesse do professor em manter seu desenvolvimento profissional faz-se necessário.

Todavia, o desenvolvimento profissional docente compreende, além do aspecto pedagógico, as proporções sociais, morais e de afetividade, relacionadas ao fazer docente (FÁVERO; PAZINATO, 2016).

Nesse sentido, o docente que reflete a sua própria prática e a formação do saber pedagógico, participando e se envolvendo com as ações implementadas em seu local de trabalho, ofertará um ensino mais eficaz (FÁVERO; PAZINATO, 2016).

Além disso, a formação docente se dá com a socialização entre os pares, pois não há profissionalização docente individual, e se assim fosse, não haveria formação (FÁVERO; PAZINATO, 20I6).

Por isso, é com o compartilhamento de conhecimentos, e com a socialização dos saberes e experiências entre os docentes no seu ambiente de trabalho, que se constrói o profissional (NÓVOA, 2019).

Nesta perspectiva, "os formadores de professores ganham destaque quanto à responsabilidade de desenvolver a capacidade de pensar, de forma autônoma e sistemática" (FÁVERO; PAZINATO, 2016, p. 133).

Nesse viés, a base formativa a partir do pensamento crítico eleva a capacidade do professor para observar a sua prática diária, agindo sobre ela, valorizando suas ações, e o engajamento de seus pares nos trabalhos desenvolvidos em conjunto (FÁVERO; PAZINATO, 20I6)

Além disso, o pensamento crítico leva o docente ao seu campo experimental, enriquecido de valores, saberes e sentimentos. $O$ conhecimento empírico junta-se a outros saberes; produzindo novas ideias e percepções (FÁVERO; PAZINATO, 2016).

Nesse contexto, para que se tenha profissionais competentes e reflexivos, fazse necessário estudar a profissionalização docente, para que ações sejam implementadas a favor da reelaboração educacional (FÁVERO; PAZINATO, 2016).

Contudo, segundo debater a profissionalização docente significa, nesse contexto, um ponto importante, para o ensino deste século, assim como à prática reflexiva do fazer docente, do processo constante de formação, da responsabilidade e valores morais (THERRIEN; DIAS; LEITINHO, 2016)

Neste sentido, o docente que reflete a ação acaba por obter saberes particulares e simultâneos à prática cotidiana, onde ela é vista como base formativa, onde o empírico e os princípios se alinham (FÁVERO; PAZINATO, 2016). 
Porém, o descaso com a formação inicial e permanente do professor universitário, e as exigências do exercício profissional, resume a docência da educação superior a uma profissão aquém do esperado (THERRIEN; DIAS; LEITINHO, 2016).

Nesse viés, faz-se necessário que os cursos de formação universitária integrem, de forma objetiva, a formação de pesquisador ao compromisso da formação docente (THERRIEN; DIAS; LEITINHO, 2016)

Desse modo, evidencia-se a forma permanente do sujeito docente no seu campo de atuação, caracterizando as práticas pedagógicas e de pesquisa, integrando essas ações, e mostrando a interação dos meios formativos (FÁ VERO; PAZINATO, 2016).

Nesse sentido, intervenções com implementações de diretrizes e ações pedagógicas que levem à uma aprendizagem significativa para discentes e sociedade, é de suma importância (THERRIEN; DIAS; LEITINHO, 20I6).

Assim sendo, quando se percebe a intervenção docente junto a aprendizagem do sujeito discente, admite-se uma ação profissional conectada as concepções teóricas (THERRIEN; DIAS; LEITINHO, 2016).

Contudo, há o confronto em mudar teoria à prática com ações interventivas, buscando como solução a compreensão dos saberes, que modificam o sujeito discente, para que assim, perceba a coerência na forma de se ver como um ser social (THERRIEN; DIAS; LEITINHO, 20I6).

Nesse contexto, (FÁVERO; PAZINATO, 2016), ressalta que "é na prática refletida que o saber se produz, é a utilização do conhecimento teórico com a sua prática na experiência cotidiana; possibilita a autêntica emancipação e a própria autonomia.

Por isso que, a atuação docente requer competência dos saberes, que serão repassados aos discentes e seriedade, como os requeridos em outras profissões (THERRIEN; DIAS; LEITINHO, 20I6).

Nesse viés, segundo (THERRIEN; DIAS; LEITINHO, 20I6), quando se percebe a prática docente como um elo contribuitivo do ensino superior relacionado aos discentes, admite-se então, um ensino significativo integrado aos saberes e valores.

Desse modo, o sujeito docente modifica e une os conhecimentos discentes àqueles construídos pela sociedade, com o propósito de uma evolução socioprofissional de seus aprendizes (THERRIEN; DIAS; LEITINHO, 20I6).

Contudo, faz-se necessário implementar ações para a formação do professor, para que tenhamos sujeitos compromissados com o ensino universitário e, mais oferta de cursos de pós-graduação, e verba voltada ao estudo da docência universitária (THERRIEN; DIAS; LEITINHO, 20I6).

Sendo assim, é necessário que a pós-graduação alinhe a formação do profissional da pesquisa à do profissional de ensino, unindo as concepções teóricas e as práticas pedagógicas, ações que virão com políticas públicas implementadas (THERRIEN; DIAS; LEITINHO, 20I6). 
Nesse contexto, vem-se percebendo ações transformadoras nas universidades, buscando, não só uma a reorganização curricular, mas também inovações na abordagem do ensino, destacando novos conceitos e variações teórico-pedagógicos (THERRIEN; DIAS; LEITINHO, 20I6).

Nesse sentido, quando as intervenções pedagógicas conectam teoria-açãoreflexão-ação, às singularidades discentes, estes se transformam num ser reflexivocrítico, pela ressignificação do processo de ensino (THERRIEN; DIAS; LEITINHO, 2016).

Assim sendo, evidencia-se a importância do trabalho didático, onde as concepções teóricas passam às práxis pedagógicas dando significado ao processo de ensino e aprendizagem, integrando aluno e professor neste mesmo processo (THERRIEN; DIAS; LEITINHO, 20I6).

Contudo, refletir sobre a possibilidade de se criar procedimentos formativos para que se entendam conceitos político-sociais relacionados ao currículo e a didática, faz-se necessário à formação docente (THERRIEN; DIAS; LEITINHO, 20I6).

Nesse viés, a formação do sujeito docente deve ser contínua, e analisada a partir de sua prática, no seu cotidiano em sala de aula, e ao longo da sua carreira, e não apenas inicialmente (VILELA, 2016).

Assim sendo, cabe ao docente se ver como profissional aberto às mudanças e críticas, atuando de forma compartilhada com seus pares, refletindo, agindo, reformulando e recriando saberes, e sempre os conectando às necessidades de aprendizagens discentes (VILELA, 2016).

\section{CONCLUSÃO}

O objetivo do presente artigo foi pesquisar as formas de intervenção para aprimorar a formação do professor formador que atua no ensino superior.

O ensino superior, no geral, tem se mostrado muito frágil no que tange a formação do professor universitário, e isso se reflete na qualidade do ensino que se oferta aos discentes, na formação dos futuros profissionais.

Apesar de, iniciativas estarem sendo tomadas, pelas instituições e pelo governo, para mudar o quadro atual, os esforços precisam ser intensificados com novas diretrizes, e políticas públicas, que possam implementar as transformações.

Sendo assim, o engajamento para se buscar formas de ofertar um ensino melhor à sociedade, deve partir de vários segmentos, que veem na educação o caminho para uma sociedade mais justa.

Nesse viés, entende-se a importância da formação continuada, como uma prática a ser seguida pelos docentes que se preocupam com o resultado do seu trabalho, e que sabem o real significado de ser professor. 
Desse modo, cabe ao docente buscar se aprimorar, tornando-se, não apenas um detentor de conhecimentos e saberes teóricos, mas, também, um implementador das práxis pedagógicas, tão essencial à sua atuação.

Pois, a formação leva à reflexão, à inovação, à criação de um novo pensamento, que consequentemente leva ao replanejamento das ações e, à avaliação e reavaliação do próprio trabalho, intervenções importantes à prática docente.

Nessa perspectiva, faz-se necessário que as instituições e órgãos competentes ofereçam, aos docentes, as condições necessárias para que estes possam continuar investindo em sua formação profissional.

Sendo assim, não se pode ofertar ensino de qualidade sem antes pensar em um profissional preparado para desenvolver esta função. Por isso, a docência exige um sujeito reflexivo, colaborativo, e sabedor de seu papel, enquanto formador de cidadãos críticos na construção de uma sociedade menos desigual.

\section{REFERÊNCIAS}

ABREU, N. Intervenção Pedagógica: como realizar em sala de aula. Disponível em: <www.sistemadeensinoph.com.br/blog/intervenção-pedagogica-como-realizar-nasala-de-aula/>. Acesso em: 27 jan. 2021.

BRASIL. Lei de Diretrizes e Bases da Educação Nacional: Lei n.9394/96, de 23 de dezembro de 1996: estabelece as diretrizes e bases da educação nacional. Brasília: Diário Oficial da União, 1996.

FÁVERO, A. A.; PAZINATO, A. A PEDAGOGIA UNIVERSITÁRIA E SUAS IMPLICAÇÕES PARA UMA PRÁTICA REFLEXIVA. Revista de Ciências Humanas - Educação, v. 17, p. 127-140, 2016.

HUBERT, I. A.; FERNANDES, J. H. DE L.; GOETTEMS, L. Formação E Inicial E

Continuada Dos Professores. Disponível em: $\langle$ www.unicruz.edu.br/mercosul/pagina/anais/2015 >. Acesso em: 30 jan. 2021.

JÚNIOIR, A. P. O; LINHARES, M. M. P.; KARWOSKI, A. M. Formação docente no contexto brasileiro das instituições federais de Educação Superior. Ensaio, v. 26, n. 98, p. 52-9o, 2018.

NÓVOA, A. Os Professores e a sua Formação num Tempo de Metamorfose da Escola. Educação \& Realidade, v. 44, n. 3, p. I-15, 2019.

SOARES, C. V. C. DE O. (2005). As intervenções pedagógicas do professor em ambientes informatizados: uma realidade a ser construída. Dissertação (Mestrado em Educação) - PPGE, Universidade Federal do Rio Grande do Sul, Porto Alegre.

THERRIEN, J; DIAS, A. M. I; LEITINHO, M. C. Docência universitária. Em Aberto, p. 21-32, dez. 2016.

VILELA, N. S. (2016). DOCÊNCIA UNIVERSITÁRIA: Um estudo sobre a experiência da Universidade Federal de Uberlândia na formação de seus professores. 
Dissertação (Mestrado em Educação) - PPGE, Universidade Federal de Uberlândia, Uberlândia. 